ojs.uv.es/index.php/qfilologia/index

Rebut: 25.04.202I. Acceptat: 05.08.202I

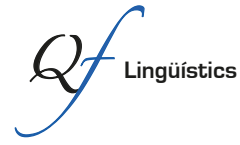

Per a citar aquest article: Garofalo, Giovanni. 202I. “'La princesa guerrera enarcó una ceja, mientras el macarra bamboleaba sus atributos bajo el pantalón'. La co-construcción narrativa del homoerotismo en internet”. Quaderns de Filologia: Estudis Lingüístics XXVI: 43-73.

doi: $10.7203 / Q$ F.26.21977

\title{
"La princesa guerrera enarcó una ceja, mientras el macarra bamboleaba sus atributos bajo el pantalón”. La co-construcción narrativa del homoerotismo en internet
}

\author{
"The warrior princess raised an eyebrow, while the pimp dangled his nuts below \\ his trousers". The narrative co-construction of homoeroticism on the web
}

GIOVANNI GAROFALO

Università degli Studi di Bergamo giovanni.garofalo@unibg.it

Resumen: Compaginando algunos conceptos medulares de la sociología y del psicoanálisis freudiano con la metodología de la lingüística de corpus, el presente trabajo se inscribe en la senda de los estudios queer de enfoque cuantitativo (Baker, 2004, 2005, 20I4, 20I8; King, 2015; Milani, 20I3) sobre la producción y la regulación social de la sexualidad y del género, para explorar el papel del lenguaje en la construcción del imaginario erótico de una comunidad gay hispanohablante en internet. Con la ayuda de Sketch Engine, se analizan las palabras clave de un corpus de relatos eróticos amateur, gais y lesbianos, para arrojar luz sobre las representaciones simbólicas y los mecanismos discursivos que guían la co-construcción del deseo erótico homosexual, masculino y femenino, en internet. Añadiendo matices significativos para el ámbito cultural hispano, los resultados del análisis confirman la tesis mantenida por Baker (2005), según la cual, al narrar encuentros sexuales fuertemente idealizados, la comunidad homosexual sigue reproduciendo y perpetuando arquetipos ancestrales heteronormativos.

Palabras clave: estudios queer; heteronormatividad; construcción social del deseo; keyness.

\begin{abstract}
Combining core concepts of sociology and Freudian psychoanalysis with the corpus linguistics methodology, this paper follows in the wake of previous quantitative queer studies on the social production and regulation of sexuality and gender (Baker, 2004, 2005, 2014, 20I8; King, 20I5; Milani, 20I3), in order to explore the role of language in the construction of the erotic imaginary of a Spanish-speaking gay community on the Web. Using Sketch Engine, the keywords of a corpus of amateur gay and lesbian erotica were analyzed to shed light on the symbolic representations and discursive mechanisms that guide the co-construction of homosexual erotic desire on the Web. Adding significant nuances relevant for the Hispanic culture, the results of the analysis confirm the thesis maintained by Baker (2005), according to which
\end{abstract}


internet homosexual communities continue to reproduce and perpetuate ancestral heteronormative archetypes in their narratives of highly idealized sexual encounters.

Keywords: Queer studies; heteronormativity; social construction of desire; keyness.

\section{Introducción y conceptos básicos}

En nuestra época dominada por la comunicación digital, internet se ha convertido en un espacio privilegiado de autorrepresentación del Yo (Self) de los usuarios, máxime cuando estos cuentan con una identidad tradicionalmente estigmatizada como la homosexual (Valdez Vázquez, 20I7: 40). Gracias al anonimato asegurado por el ciberespacio, el internauta deja entrever aspectos esenciales de su ser que no suele mostrar o comentar con facilidad en contextos cotidianos de interacción cara a cara. Este es, justamente, el caso de las narraciones eróticas en la red, que, en la mayoría de los casos, no tienen ningún viso de verosimilitud y solo apuntan a excitar a sus receptores, ofreciendo representaciones de "las mejores aventuras sexuales posibles" (Baker, 2005: 154).

Desde la vertiente discursiva, los relatos eróticos homosexuales disponibles en internet constituyen un ámbito de investigación de gran interés para los estudios queer (o cuir), relacionados con la construcción social de la orientación sexual y de la identidad de género de personas lésbicas, gais, transgénero, bisexuales e intersexuales (LGTBI). Tras originarse en el ámbito de la teoría literaria (Kosofsky Sedgwick, I985; De Lauretis, I99I), dichos estudios se han expandido a una pluralidad de disciplinas académicas, incluido el análisis crítico del discurso (Harvey \& Shalom, I997; Motschenbacher, 2018, 2019; Leap, 20I5), también en su versión asistida por corpus (Baker, 2004, 2005, 20I4, 20I8; King, 20I5; Milani, 2013), lo cual indica que lo queer constituye un terreno de investigación proclive a las triangulaciones metodológicas. El conjunto de estos estudios suele distinguir las nociones de sexualidad y de género (Giddens \& Sutton, 20I7), desprovistas de cualquier fundamento biológico e interpretadas como constructos sociales e históricos que acaban moldeando las identidades básicas de los sujetos. Así pues, si el sexo es una característica física que permite la distinción biológica entre el varón y la hembra de cada especie, el género indica las expectativas culturales construidas socialmente alrededor de mujeres y hombres que, tras un proceso de naturalización de lo social y de socialización de lo biológico, acaban cobrando carta de naturaleza (Strelkov, 2004: II). 
Desde esta perspectiva, la identidad de género debe entenderse como un sistema de relaciones y representaciones durables (no como una esencia), adquiridas a lo largo de la interacción entre individuos y forjadas por las estructuras sociales. Dicha identidad coincide con la percepción que una persona tiene de sí misma y que la lleva a identificarse, según los casos, con una mujer, con un hombre o con la combinación de ambos. De ahí que, por expresividad de género, entendamos la comunicación de la identidad de género de una persona a través de su comportamiento, su forma de vestirse, peinarse o autorrepresentarse. La manera en la que los internautas homosexuales construyen lingüísticamente sus deseos eróticos es una de las múltiples facetas de su expresividad de género y la mayoría de las personas se inclinaría a pensar que dichas fantasías, en ocasiones tan transgresivas y extremas, son la expresión más auténtica de una subjetividad anticonformista y rompedora. Es esta, sin embargo, una crasa falacia: si, por un lado, el colectivo LGTBI ha reivindicado orgullosamente, cual rasgo identitario, un deseo erótico que la sociedad consideraba desviado y degradado, estudios de corte sociológico indican que este deseo queda paradójicamente plasmado por el mismo simbolismo patriarcal y heteronormativo (Connell, I995; Ciccone, 2019) que ha marginalizado a los homosexuales durante siglos. De hecho, ya en el año I975 Foucault avisaba de que el deseo y la subjetividad no son solo reprimidos sino también construidos socialmente, ya que

[el poder] no se limita a reprimir, reducir el acceso a la realidad e impedir la formulación de un discurso: el poder trabaja el cuerpo, penetra en el comportamiento, se entremezcla con el deseo y con el placer y es, justamente, en esta labor en donde hay que sorprenderlo, y este análisis, que es difícil, es el que es oportuno realizar (Foucault, I975, en Ciccone, 20I9: II4, traducción propia).

La masculinidad heteronormativa, en suma, seguiría siendo la pauta social penetrante que, con sus construcciones lingüísticas y sus representaciones simbólicas, acaba "colonizando" hasta los terrenos más "excéntricos" y periféricos del deseo y de la pasión, como aquellos del erotismo LGTBI.

El propósito del presente estudio consiste precisamente en poner a prueba la referida teoría construccionista del deseo gay y lésbico, analizando cómo el

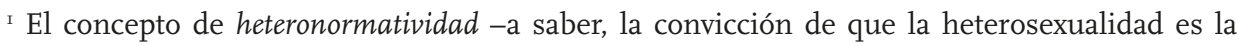
única orientación sexual posible y que las únicas relaciones sexuales y conyugales apropiadas son aquellas entre individuos de sexo opuesto- fue introducido por Michael Warner en I99I, en una de las primeras obras pioneras de la teoría queer.
} 
homoerotismo de una comunidad virtual de usuarios queda plasmado en un corpus de relatos amateur en español (26.506.383 palabras $\left.{ }^{2}\right)$, organizado en un subcorpus gay (35I6 relatos, I2.684.8I4 palabras) y en otro lésbico (3346 relatos, I3.821.569 palabras). Los relatos seleccionados, escritos entre 2010 y 202I por 6I2 autores y 609 autoras 3 , se han extraído del portal web Todorelatos (https://www.todorelatos.com/), comunidad virtual que reúne homosexuales de España e Hispanoamérica, quienes comparten espontáneamente sus propias narraciones con los demás lectores, realizando a diario una labor colectiva y colaborativa de co-construcción y afianzamiento de un imaginario erótico supuestamente "no convencional", polimorfo y polifacético. De hecho, en el portal los relatos se clasifican en 33 subcategorías distintas, desde los bisexuales, fetichistas, de control mental, sexo oral, anal o dominación hasta los relatos gais, lésbicos, interraciales, transexuales, voyeristas, zoófilos, etc.

En el estudio pionero de Baker (2005: 155, 247) en el que se basa esta investigación, el citado autor arguye que es metodológicamente más provechoso comparar narraciones gais y lésbicas que cuentos gais y heterosexuales, ya que los protagonistas de las narraciones homosexuales suelen compartir la misma identidad de género. En cambio, es más complejo llevar a cabo un análisis automatizado de relatos eróticos heteros, en los que aparecen personajes masculinos y femeninos, ya que, para evaluar los discursos que se esconden tras los elementos lingüísticos, el/la analista debería realizar un etiquetado previo de cada enunciado, para establecer si el emisor/destinatario es un hombre o una mujer, tarea no sencilla, sobre todo en secuencias narrativas no dialogadas. Este trabajo se adhiere al criterio de Baker y opta por cotejar cuentos eróticos gais y lésbicos, un contraste susceptible de revelar cómo cada una de estas categorías de la comunidad LGTBI construye lingüísticamente su propia identidad y la de su pareja sexual ideal, el tipo de prácticas eróticas objeto de sus ensoñaciones, la distribución más o menos esperable de los roles sexuales, el lenguaje que cada subcategoría de autores/receptores encuen-

\footnotetext{
${ }^{2}$ Agradezco al Dr. Javier Fernández Cruz, de la Universidad de Málaga, su valiosa ayuda para recopilar, etiquetar y limpiar el corpus de estudio.

${ }^{3}$ Al confeccionar el corpus, se ha procurado conseguir un equilibrio entre el aporte individual de cada autor/a y el número total de relatos, teniendo en cuenta que, en toda comunidad virtual, siempre hay miembros más activos que otros. El autor más prolífico del subcorpus gay (Albany) es responsable de apenas el $4.63 \%$ de los cuentos masculinos, mientras que, en el subcorpus lésbico, la autora más productiva (Atenea) tiene en su haber el 6,3\% de los relatos femeninos estudiados.
} 
tra excitante en las situaciones representadas y, en general, los discursos que orientan las representaciones simbólicas de la sexualidad de gais y lesbianas.

Otras cuestiones señaladas por Baker atañen a la identidad de los autores de los relatos y al supuesto contenido "indecente" de las narraciones. Es indudable que el anonimato garantizado por el medio virtual no permite inferir sin errores la verdadera identidad de los autores ni su edad o ubicación geográficas. De hecho, todos los miembros de la comunidad Todorelatos.com utilizan un pseudónimo y su variedad dialectal no resulta siempre coherente con el país de residencia declarado. Solo podemos conjeturar que el deseo erótico de cada autor se encauza en la subcategoría del portal a la que decide subir sus relatos, para compartirlos con los demás internautas, que supuestamente albergan un imaginario erótico similar

Con respecto al contenido de las narraciones, la realización de un estudio de esta índole plantea un dilema terminológico sobre la oportunidad de clasificar los relatos como eróticos o pornográficos. La mayoría de los profesionales del campo de la psicología y la sociología parecen coincidir en que hoy la linde entre erotismo y pornografía es bastante borrosa, ya que los dos conceptos tienden a solaparse y la decisión de clasificar un texto como erótico o pornográfico depende solo de criterios culturales y de los cánones éticos o estéticos de cada cual.

\section{Análisis de las palabras clave}

Es sabido que el análisis de palabras clave (keyword analysis) se centra en las unidades léxicas que no son necesariamente las más recurrentes en el corpus de estudio, sino las que presentan una frecuencia peculiar o inesperada. De hecho, la noción de keyness (traducible al español como "valor de palabras clave") fue introducida a finales de los años noventa del siglo pasado por Mike Scott (I997: 236), quien definió la "palabra clave" (keyword) como "a word which occurs with unusual frequency in a given text [...] by comparison with a reference corpus of some kind". Las palabras clave se obtienen mediante el cotejo de dos conjuntos de textos, en el cual uno de ellos sirve de "referencia". Su extracción se realiza con la ayuda de un software que compara las frecuencias de cada palabra en los dos corpus, mediante un test de significancia estadística que considera el tamaño de cada corpus y la frecuencia normalizada de cada palabra (Baker, 20I8: 79). El valor de palabras clave de los ítems extraídos mediante este procedimiento se relaciona íntimamente con los contenidos 
del corpus (aboutness), a saber, con las nociones medulares, actitudes y conceptualizaciones de la realidad que vertebran los textos de estudio (Phillips, I989: 7-10, 26, 53-54; Gabrielatos, 20I8: 225-226).

Por este conjunto de razones, el examen de las palabras clave es una técnica valiosa de análisis crítico del discurso asistido por corpus (Partington, Duguid \& Taylor, 20I3), ya que, al ser el resultado de un cálculo estadístico, las keywords son puntos de referencia sólidos o "señales de tráfico" que guían el recorrido del analista hacia la ansiada objetividad (signposts to objectivity, en palabras de Baker, 20I8), lo que le permite, a la vez, detectar huellas de determinados discursos que anidan en los textos examinados. Empleamos aquí el término discurso en el sentido indicado por Foucault (I969) desde las ciencias sociales, a saber, como prácticas que forman sistemáticamente los objetos de los que hablan. Se trata de un conjunto de convenciones, saberes y actividades sociales que determinan la percepción que el individuo tiene de lo "real" y su comportamiento resultante, siendo el lenguaje una de las prácticas más poderosas que moldean los discursos (Harvey \& Shalom, I997: 7). A este respecto, cabe recordar que, por sí solos, los ítems clave no son capaces de revelar un particular sesgo ideológico y que el aporte interpretativo del/de la analista sigue siendo decisivo:

discourses emerge as much through our work of reading as from the text. Keywords will therefore not reveal discourses, but will direct the researcher to important concepts in a text (in relation to other texts) that may help to highlight the existence of types of (embedded) discourse and ideology (Baker, 2004: 347).

La posibilidad de rastrear indicios de discursos o ideologías hegemónicas dependerá, en buena medida, del corpus de cotejo que se elija y de cómo el/la analista seleccione y relacione entre sí las palabras clave. En general, el análisis automatizado genera una lista muy amplia de keywords susceptibles de orientar el recorrido hermenéutico, que es imposible analizar en su totalidad. Así pues, es oportuno realizar, de entrada, una serie de elecciones metodológicas sobre: a) los umbrales de frecuencia de las palabras clave que se van a considerar, habida cuenta de la extensión de los corpus de enfoque y de referencia; b) los corpus que se pretende comparar; $c$ ) los criterios temáticos-discursivos que se van a esgrimir para seleccionar e hilvanar entre sí los ítems clave. Detectar discursos hegemónicos incrustados, por tanto, significa mirar más allá del simple listado de palabras clave generado por el software 
y profundizar en un examen de concordancias de los ítems seleccionados, de su comportamiento colocacional y de su preferencia y prosodia semántica4.

Para este estudio, los dos subcorpus de narraciones se han analizado mediante la herramienta Sketch Engine5 (Kilgarriff et al., 2004), que permite gestionar corpus muy amplios y extraer palabras clave únicas y compuestos sintagmáticos con valor clave (multi-word terms). Para enfocar la búsqueda, se ha establecido el valor i en la escala comprendida entre los extremos de lo raro y de lo común, con una frecuencia mínima de 20 casos y limitando a Iooo el número máximo de keywords, para que las palabras así obtenidas resulten suficientemente significativas. Asimismo, siguiendo a Baker (2005: I6I), se han considerado solo las palabras y compuestos clave que aparecen al menos en 25 textos distintos de cada subcorpus, excluyendo, de este modo, aquellas concentradas en un número demasiado reducido de textos.

Con carácter preliminar, para descubrir qué léxico prevalece en los dos subcorpus con respecto al español general, se ha utilizado como referencia el corpus Spanish Web 2018 de Sketch Engine (i6.951.839.897 palabras), que presenta la ventaja de ser una muestra muy representativa del español escrito, europeo y americano, en internet. Este cotejo nos introduce en el universo discursivo de los relatos, ofreciéndonos una visión inmediata de las temáticas y del tipo de lenguaje que predominan en cada subcorpus, como se aprecia en las tablas siguientes, que recogen los 30 primeros lemas clave detectados en los relatos gais (tabla I) y lésbicos (tabla 2):

\footnotetext{
4 Preferencia semántica y prosodia semántica son dos conceptos aledaños que se remontan a los estudios de Sinclair (I987, I996) y Louw (I993), inspirados en la tradición firthiana, sobre las colocaciones y las "unidades extendidas de significado" (extended units of meaning), que demuestran que los significados no residen en palabras aisladas, sino que se originan en segmentos discursivos más amplios. Aunque estén estrechamente relacionados, es conveniente distinguir dichos conceptos entendiendo por preferencia semántica (semantic preference) el campo semántico predominante al que pertenecen los colocativos de una determinada palabra, mientras que la prosodia semántica (semantic prosody) se refiere sobre todo a la evaluación, positiva o negativa, sugerida por los elementos que coaparecen con una unidad léxica.

5 http://www.sketchengine.eu [02/202I]
} 


\begin{tabular}{|c|c|c|c|c|c|c|c|c|}
\hline & \multirow[t]{2}{*}{ Forma } & \multicolumn{2}{|c|}{$\begin{array}{l}\text { Frec. por millón } \\
\text { (f.p.m.) }\end{array}$} & \multicolumn{2}{|c|}{ N. documentos } & \multicolumn{2}{|c|}{ Relative DOCF } & \multirow[t]{2}{*}{ Punt. } \\
\hline & & Enfoque & Referencia & Enfoque & Referencia & Enfoque & Referencia & \\
\hline 1 & polla & 1801,68 & 6,35 & 1900 & 61,027 & $54,04 \%$ & $0,10 \%$ & 245,3 \\
\hline 2 & verga & 955,39 & 3,13 & 1225 & 27.304 & $34,84 \%$ & $0,05 \%$ & 231,5 \\
\hline 3 & culo & 1409,01 & 12,62 & 2211 & 166.202 & $62,88 \%$ & $0,28 \%$ & 103,5 \\
\hline 4 & gemir & 384,55 & 3,01 & 1613 & 37.635 & $45,88 \%$ & $0,06 \%$ & 96,1 \\
\hline 5 & glande & 192,20 & 1,06 & 1043 & 11.545 & $29,66 \%$ & $0,02 \%$ & 93,9 \\
\hline 6 & nalga & 339,15 & 2,76 & 1402 & 37.493 & $39,87 \%$ & $0,06 \%$ & 90,5 \\
\hline 7 & semen & 373,44 & 3,28 & 1517 & 38.143 & $43,15 \%$ & $0,06 \%$ & 87,6 \\
\hline 8 & culito & 181,40 & 1,10 & 673 & 15.843 & $19,14 \%$ & $0,03 \%$ & 86,9 \\
\hline 9 & lamer & 373,91 & 3,65 & 1576 & 50.528 & $44,82 \%$ & $0,09 \%$ & 80,7 \\
\hline 10 & follar & 716,45 & 8,11 & 1742 & 81.645 & $49,54 \%$ & $0,14 \%$ & 78,7 \\
\hline 11 & masturbar & 256,45 & 2,68 & 1279 & 34.814 & $36,38 \%$ & $0,06 \%$ & 69,9 \\
\hline 12 & calzoncillo & 145,45 & 1,11 & 805 & 17.520 & $22,90 \%$ & $0,03 \%$ & 69,3 \\
\hline 13 & rabo & 231,22 & 2,37 & 770 & 38.505 & $21,90 \%$ & $0,06 \%$ & 68,9 \\
\hline 14 & gemido & 213,96 & 2,21 & 1308 & 27.251 & $37,20 \%$ & $0,05 \%$ & 67,1 \\
\hline 15 & bóxer & 102,80 & 0,57 & 599 & 8101 & $17,04 \%$ & $0,01 \%$ & 66,0 \\
\hline 16 & chupar & 480,81 & 6,58 & 1610 & 97.542 & $45,79 \%$ & $0,16 \%$ & 63,6 \\
\hline 17 & lefa & 65,27 & 0,09 & 453 & 1504 & $12,88 \%$ & $<0,01 \%$ & 60,9 \\
\hline 18 & capullo & 139,69 & 1,39 & 732 & 21,479 & $20,82 \%$ & $0,04 \%$ & 58,9 \\
\hline 19 & ojete & 82,07 & 0,43 & 405 & 7538 & $11,52 \%$ & $0,01 \%$ & 57,9 \\
\hline 20 & mamada & 137,80 & 1,51 & 983 & 22.429 & $27,96 \%$ & $0,04 \%$ & 55,2 \\
\hline 21 & cipote & 59,05 & 0,11 & 220 & 1741 & $6,26 \%$ & $<0,01 \%$ & 54,2 \\
\hline 22 & besar & 911,64 & 15,96 & 2343 & 175.736 & $66,64 \%$ & $0,30 \%$ & 53,8 \\
\hline 23 & ooohhh & 53,53 & 0,03 & 104 & 508 & $2,96 \%$ & $<0,01 \%$ & 53,0 \\
\hline 24 & $\mathrm{mmm}$ & 193,54 & 2,67 & 395 & 43.655 & $11,23 \%$ & $0,07 \%$ & 53,0 \\
\hline 25 & aaahhh & 53,06 & 0,06 & 114 & 1031 & $3,24 \%$ & $<0,01 \%$ & 51,2 \\
\hline 26 & acariciar & 564,61 & 10,35 & 1954 & 132.656 & $55,57 \%$ & $0,22 \%$ & 49,8 \\
\hline 27 & follada & 68,90 & 0,41 & 488 & 6700 & $13,88 \%$ & $0,01 \%$ & 49,5 \\
\hline 28 & maricón & 90,27 & 0,92 & 432 & 13.746 & $12,29 \%$ & $0,02 \%$ & 47,4 \\
\hline 29 & slip & 69,06 & 0,48 & 373 & 7578 & $10,61 \%$ & $0,01 \%$ & 47,4 \\
\hline 30 & cabrón & 170,36 & 2,74 & 782 & 43.273 & $22,24 \%$ & $0,07 \%$ & 45,8 \\
\hline
\end{tabular}

Tabla I. Primeros 30 lemas clave del subcorpus gay. Referencia: Spanish Web 2018 
"La princesa guerrera enarcó una ceja, mientras el macarra bamboleaba..."

\begin{tabular}{|c|c|c|c|c|c|c|c|c|}
\hline & \multirow[t]{2}{*}{ Forma } & \multicolumn{2}{|c|}{$\begin{array}{l}\text { Frec. por millón } \\
\text { (f.p.m.) }\end{array}$} & \multicolumn{2}{|c|}{ N. documentos } & \multicolumn{2}{|c|}{ Relative DOCF } & \multirow{3}{*}{$\begin{array}{l}\text { Punt. } \\
402,9\end{array}$} \\
\hline & & Enfoque & Referencia & Enfoque & Referencia & Enfoque & Referencia & \\
\hline 1 & Xena & 458,49 & 0,14 & 80 & 1428 & $2,39 \%$ & $<0,01 \%$ & \\
\hline 2 & Gabrielle & 425,06 & 0,44 & 89 & 5423 & $2,66 \%$ & $<0,01 \%$ & 294,9 \\
\hline 3 & Alely & 188,91 & $<0,01$ & 16 & 46 & $0,48 \%$ & $<0,01 \%$ & 189,4 \\
\hline 4 & Sophia & 338,75 & 0,84 & 37 & 11.129 & $1,11 \%$ & $0,02 \%$ & 184,8 \\
\hline 5 & Kiara & 178,63 & 0,38 & 32 & 3191 & $0,96 \%$ & $<0,01 \%$ & 130,6 \\
\hline 6 & Xenia & 119,31 & 0,15 & 16 & 2105 & $0,48 \%$ & $<0,01 \%$ & 104,9 \\
\hline 7 & Sonjay & 99,99 & $<0,01$ & 11 & 98 & $0,33 \%$ & $<0,01 \%$ & 100,2 \\
\hline 8 & Casandra & 128,7 & 0,32 & 13 & 3906 & $0,39 \%$ & $<0,01 \%$ & 98,1 \\
\hline 9 & Scarlet & 127,34 & 0,43 & 38 & 5268 & $1,14 \%$ & $<0,01 \%$ & 89,7 \\
\hline 10 & Bardo & 156,13 & 0,83 & 60 & 12.199 & $1,769 \%$ & $0,02 \%$ & 85,7 \\
\hline 11 & Emma & 483,59 & 4,77 & 66 & 57.689 & $1,97 \%$ & $0,10 \%$ & 83,9 \\
\hline 12 & Ronnie & 122,78 & 0,62 & 26 & 7967 & $0,78 \%$ & $0,01 \%$ & 76,5 \\
\hline 13 & Vane & 96,08 & 0,31 & 101 & 3807 & $3,02 \%$ & $<0,01 \%$ & 74,0 \\
\hline 14 & Mariana & 182,76 & 1,64 & 126 & 24.489 & $3,77 \%$ & $0,04 \%$ & 69,5 \\
\hline 15 & Fer & 158,95 & 1,42 & 142 & 18.860 & $4,24 \%$ & $0,03 \%$ & 66,0 \\
\hline 16 & besar & 1071,66 & 15,96 & 2357 & 175.736 & $70,44 \%$ & $0,30 \%$ & 63,2 \\
\hline 17 & guerrera & 124,52 & 1,02 & 91 & 16.331 & $2,72 \%$ & $0,03 \%$ & 62,3 \\
\hline 18 & Zoe & 131,82 & 1,18 & 17 & 14.097 & $0,51 \%$ & $0,02 \%$ & 61,0 \\
\hline 19 & Jess & 93,40 & 0,57 & 45 & 5275 & $1,34 \%$ & $<0,01 \%$ & 60,2 \\
\hline 20 & clítoris & 154,40 & 1,68 & 707 & 19.583 & $21,13 \%$ & $0,03 \%$ & 58,0 \\
\hline 21 & Fernanda & 257,93 & 3,48 & 191 & 53.207 & $5,71 \%$ & $0,09 \%$ & 57,8 \\
\hline 22 & Karla & 186,38 & 2,26 & 103 & 24.987 & $3,08 \%$ & $0,04 \%$ & 57,4 \\
\hline 23 & Desi & 67,79 & 0,18 & 10 & 2399 & $0,30 \%$ & $<0,01 \%$ & 58,5 \\
\hline 24 & Valeria & 229,42 & 3,03 & 107 & 42.723 & $3,20 \%$ & $0,07 \%$ & 57,2 \\
\hline 24 & Cami & 73,58 & 0,32 & 112 & 4802 & $3,35 \%$ & $<0,01 \%$ & 56,4 \\
\hline 25 & Alein & 55,06 & $<0,01$ & 8 & 36 & $0,24 \%$ & $<0,01 \%$ & 55,9 \\
\hline 27 & Jaaz & 53,47 & $<0,01$ & 1 & 25 & $0,03 \%$ & $<0,01 \%$ & 54,4 \\
\hline 28 & Aiden & 66,92 & 0,28 & 23 & 1999 & $0,69 \%$ & $<0,01 \%$ & 52,9 \\
\hline 29 & Annette & 65,41 & 0,32 & 10 & 4724 & $0,30 \%$ & $<0,01 \%$ & 50,1 \\
\hline 30 & Any & 84,94 & 0,84 & 76 & 12.556 & $2,27 \%$ & $0,02 \%$ & 46,6 \\
\hline
\end{tabular}

Tabla 2. Primeros 30 lemas clave del subcorpus lésbico. Referencia: Spanish Web 2018 
Cada tabla ofrece la frecuencia normalizada por millón (f. p. m.) en el subcorpus de enfoque y en el de referencia, el número de documentos en el que aparece cada ítem, el porcentaje de documentos que contienen cada palabra clave (Relative DOCF) y la puntuación (valor de keyness), calculada con el método de simple maths aplicado por Sketch Engine. Observando la tabla I, notamos que la mayoría de los lemas clave gay son sustantivos, de registro informal, vulgar u obsceno, relacionados con ropa interior y partes anatómicas masculinas o bien con prácticas sexuales entre hombres (gendered keywords), siendo algunos más frecuentes en los textos donde prevalece la variante diatópica americana (p. ej., verga). Notamos también la presencia de siete lemas verbales (en orden de frecuencia: gemir, lamer, follar, masturbar, chupar, besar, acariciar), que, como era previsible, remiten a la práctica del sexo entre hombres. Si, para profundizar en el análisis, desglosamos el lema follar en las correspondientes formas clave, descubrimos que el ítem follarme aparece empleado, en el $94 \%$ de los casos, por una voz narrativa que desempeña el rol sexual pasivo (a saber, el papel semántico de paciente, p. ej., empezó a follarme más y más fuerte) y solo en un $6 \%$ de casos el rol activo (o papel semántico de agente, p. ej., mi vida es follarme a todos los tíos que me da la gana), lo cual parece indicar que la mayoría de las fantasías vertidas en el subcorpus gay son fabulaciones eróticas de personajes pasivos. Este dato parece coherente con el valor contextual del participio follado (empleado, en el $64 \%$ de los casos, para indicar al protagonista pasivo ${ }^{6}$, p. ej., sí, papi, me has follado divino, mientras solo en el $24 \%$ de los casos se refiere a la penetración realizada por un activo, p. ej., ya me he follado a machos hetero con pareja) y solo en el I2 \% de los contextos indica la acción general de tener sexo, sin definición de roles (¿Te refieres a si he follado con un tío?). Asimismo, en las narraciones gay descuellan algunas interjecciones (ooohh , $\mathrm{mmm}$, aaahh) asociadas al momento culminante del goce sexual, además de unos apelativos insultantes (p. ej., capullo7 o cabrón), empleados en ocasiones en sentido ponderativo de camaradería (p. ej., iqué capullo eres!, ¿̇Te gusta, cabrón?).

En cambio, si nos fijamos en los primeros 30 lemas clave del subcorpus lésbico, destacan por su keyness 27 nombres propios de mujeres (es decir, el 90\% de la muestra, siete de ellos, a saber, el 25,9\% de dichos nombres, empleados

\footnotetext{
${ }^{6}$ Porcentajes calculados a partir del despojo manual de una muestra aleatoria de 50 concordancias de las formas follarme y follado.

7 En una muestra aleatoria de 50 concordancias de capullo, en 47 casos (94\%) la palabra indica el glande y en 3 casos (6\%) está empleada como apelativo.
} 
como hipocorísticos: Ronnie, Vane, Fer, Jess, Desi, Cami, Any8), un único lema verbal (besar) y dos sustantivos (clítoris, guerrera). Se aprecia, además, la ausencia de léxico obsceno o soez y el uso preferente del lema besar con colocativos que construyen el marco idílico de un encuentro romántico (p. ej., besándonos tiernamente; besó suavemente sus labios; seguí besando [su cuello] mientras mis dedos la acariciaban). Como puede observarse, comparar las palabras clave con el mayor índice de keyness en los dos subcorpus sirve solo para destacar las diferencias más obvias y esperables: a simple vista, los gais parecen más proclives a prácticas sexuales promiscuas sin sentimiento, expresión de puro goce genital que ansía la penetración y la eyaculación, mientras que las lesbianas resultarían supuestamente más íntimas, entregadas y efusivas (de ahí el uso preponderante de hipocorísticos en su lenguaje), menos "penetradoras" que los hombres y principalmente enfocadas hacia la estimulación delicada de las áreas erógenas de sus cuerpos. A este respecto, parece significativo que el primer compuesto sintagmático que contiene el ítem beso sea beso tierno en los relatos lésbicos (f. p. m.: Io,3) y beso negro en los gais (f. p. m.: 8,4). Esta primera ojeada al léxico clave de los dos subcorpus, sin embargo, deja entrever solo algunos tópicos y no nos revela mucho más acerca de las ideologías y de los discursos que orientan la creación discursiva del erotismo de gais y lesbianas. Para profundizar en el análisis, por tanto, será oportuno comparar entre sí ambos subcorpus y mirar más allá del índice de keyness y de la categoría gramatical o semántica de los ítems clave. Y es que una lista de keywords puede revelar diferencias a nivel léxico, pero no es capaz de explicar, por sí misma, el porqué de estas diferencias. La idea, por tanto, es centrarse en grupos de elementos clave que, según Baker (2005: I60-6I), "have similar semantic properties or functions within the texts". No se trata de emprender el estudio a partir de una "lista de la compra" de conceptos, rasgos lingüísticos o palabras, sino de enlazar algunas keywords mediante un hilo conductor hermenéutico, que surge de las relaciones temáticas entre ítems clave, para desvelar en qué medida el deseo homosexual resulta colonizado por un simbolismo heteronormativo.

\subsection{La construcción discursiva de la sexualidad}

A diferencia de lo que Baker (2005: 162 ) observa en relatos amateur norteamericanos, en el corpus de estudio no se han detectado muestras evidentes

\footnotetext{
${ }^{8}$ Hipocorísticos de Verónica, Vanessa, Fernanda, Jessica, Desirée, Camilla y Ana.
} 
del discurso de la homosexualidad obligatoria, basado en el tópico de que "la ocasión hace al ladrón”, es decir, que cualquiera, si se dan las condiciones propicias, puede llegar a disfrutar el sexo gay o lésbico, incluso mucho más que el heterosexual. Un examen puntual de los lemas clave recabados comparando entre sí ambos subcorpus no parece apuntar tanto a esta creencia como a un persistente rechazo de la condición de homosexual por parte de numerosos personajes y a su dificultad de autoaceptación, fruto de la supervivencia de una cultura machista, particularmente perceptible en los textos con rasgos diatópicos americanos. La frecuencia muy elevada de los ítems maricón, marica, mariconada (clave en los relatos gay) y lesbiana (clave en los lésbicos) delatan la presencia larvada de este discurso, como se observa en la tabla siguiente:

\begin{tabular}{|l|r|r|r|r|r|r|}
\hline Lema clave & \multicolumn{2}{|c|}{$\begin{array}{c}\text { Frecuencia normalizada por } \\
\text { millón }\end{array}$} & \multicolumn{2}{c|}{$\begin{array}{c}\text { Número de documentos que } \\
\text { contienen la palabra clave }\end{array}$} & $\begin{array}{c}\text { \% documentos que contienen } \\
\text { la palabra clave (Relative } \\
\text { DOCF) }\end{array}$ \\
\hline & T. gay & T. lésbicos & T. gay & T. lésbicos & T. gay & T. lésbicos \\
\hline maricón & 90,27 & 0,87 & 432 & 10 & $12,29 \%$ & $0,30 \%$ \\
marica & 43,28 & 2,89 & 299 & 29 & $8,50 \%$ & $0,87 \%$ \\
mariconada & 4,65 & 0,22 & 48 & 3 & $1,37 \%$ & $0,09 \%$ \\
lesbiana & 1,97 & 17,87 & 19 & 179 & $0,54 \%$ & $5,35 \%$ \\
\hline
\end{tabular}

Tabla 3. Lemas clave relativos al machismo y al conflicto interior por aceptar la homosexualidad

Sorprende no encontrar, entre las keywords del subcorpus lésbico, la palabra bollera, empleada solo i6 veces en todos los relatos sáficos (f. p. m. I,I6, en io documentos), lo cual indica cierto rechazo a ese calificativo por parte de las lesbianas de la comunidad virtual estudiada. Como era de esperar, bollera tiene también una frecuencia bajísima en el subcorpus gay (f. p. m. o,I6, dos casos en un solo texto). Si observamos las pautas colocacionales de las palabras incluidas en la tabla 3, detectamos una prosodia evaluativa (Partington 20I4) acusadamente negativa, motivada por el estigma social todavía asociado a la homosexualidad. Adviértase, p. ej., cómo los personajes de los contextos (I), (2) se empeñan en negar lo evidente, es decir, su propia atracción hacia individuos del mismo sexo, disfrazándola a menudo de bisexualidad, condición más tranquilizadora y socialmente menos estigmatizada. La homofobia latente que los miembros de la comunidad virtual parecen manifestar hacia sí mismos y las demás personas LGTBI es evidentemente el resultado de una práctica social que ha generalizado la presunción de universalidad del deseo 
heterosexual y, por ende, la repulsa al homoerotismo $(3,4)$ y el miedo a salir del armario9:

(I) Carlo, dejó el mando en el sofá, se giró, sin dejar salir la verga de Mahón de su culo, y trató de besarlo en los labios. Este le apartó la cara. - Sin besar, ¡coño! ¡Que yo no soy maricón! -Pues bien que me taladras... el culo... iiooh!!

(2) Ese es mi gran secreto, también me gusta experimentar con hombres y ahora estoy totalmente seguro. - Entonces, ¿eres marica? - No, al igual que tú soy bisexual.

(3) Lo que le impidió que ella me ayudase fue que la amenazaron con contarle a sus padres que era lesbiana.

(4) -Papa: jentonces es verdad! (se acerca y me da una cachetada) Yo no crie a una asquerosa lesbiana, las mujeres se hicieron para los hombres.

Cabe señalar que el discurso homofóbico aparece con tintas más cargadas en los relatos gais que en los lésbicos, por la omnipresencia del simbolismo fálico heterosexual que acaba moldeando el imaginario erótico gay.

Desde la vertiente psicoanalítica freudiana, la dificultad que el individuo experimenta para aceptar su propia homosexualidad se ha atribuido al control ejercido por el superyó sobre el ello. Es sabido que, en su teoría estructural de la vida psíquica, Sigmund Freud (1976/196ra) distinguió entre el ello, el yo y el superyó. El ello representa la masa de pulsiones que luchan por salir del inconsciente y está gobernada por el principio del placer. El superyó, instancia psíquica que regula el comportamiento y preside la conciencia moral, surge en el niño con la resolución del complejo de Edipo, mediante la internalización de los valores y normas de los padres. El superyó se manifiesta a través de mecanismos de autocensura o autodefensa contra el acecho del ello, provocando inhibiciones o la necesidad de autocastigarse, p. ej., despreciando y reprimiendo las pulsiones homosexuales inconscientes (Morgenthaler, I982).

En ambos subcorpus, los personajes que asumen con orgullo su homosexualidad en público y emplean la palabra maricón/marica con función empoderadora de cara al exogrupo hetero parecen ser una pequeña minoría y, paradójicamente, lo hacen reivindicando un rol sexual cargado de un simbolismo tradicional polarizado, muy "femenino" o muy "masculino", sin medias tintas. En efecto, en una muestra aleatoria de 50 concordancias de maricón y lesbiana se han encontrado solo los tres casos siguientes que dejan entrever atisbos de rebelión contra el modelo heteronormativo hegemónico:

\footnotetext{
9 En todos los ejemplos que aparecen a continuación, la cursiva añadida no aparece en los documentos originales.
} 
(5) ¿¿SABEN QUE?? [...] Sí....soy gay.....soy maricón, una loca...un chupa vergas...¿iY qué?, yo reto a que alguien me venga y me diga algo, para que vean de lo que soy capaz.

(6) Sí, soy maricón y me gusta coger culos ricos.

(7) Yo soy lesbiana y a mucho honor, y sé que siempre voy a tener que nadar contra la corriente, pero esto era demasiado.

Otra fantasía sexual recurrente (en ambos subcorpus, aunque mucho más frecuente en los relatos gais), consiste en tener una experiencia sexual con una persona mayor o madura, pulsión que puede rozar el incesto cuando la pareja sexual fantaseada es la figura paterna, un tío, un hermano mayor o hermanastro, como indican las keywords siguientes:

\begin{tabular}{|l|r|r|r|r|r|r|}
\hline \multicolumn{1}{|c|}{ Palabra clave } & \multicolumn{2}{|c|}{$\begin{array}{c}\text { Frecuencia normalizada por } \\
\text { millón }\end{array}$} & \multicolumn{2}{c|}{$\begin{array}{c}\text { Número de documentos que } \\
\text { contienen la palabra clave }\end{array}$} & \multicolumn{2}{c|}{$\begin{array}{c}\text { \% documentos que con- } \\
\text { tienen la palabra clave } \\
\text { (Relative DOCF) }\end{array}$} \\
\hline & \multicolumn{1}{|c|}{ T. gay } & T. lésbicos & \multicolumn{1}{c|}{ T. gay } & T. lésbicos & T. gay & T. lésbicos \\
\hline cincuentón & 5 & 0,4 & 30 & 5 & $0,843 \%$ & $0,148 \%$ \\
cuarentón & 6,2 & 0,9 & 47 & 10 & $1,321 \%$ & $0,296 \%$ \\
hombre maduro & 13,2 & 0,8 & 110 & 9 & $3,372 \%$ & $0,267 \%$ \\
padrastro & 11,1 & 1,9 & 40 & 16 & $1,124 \%$ & $0,474 \%$ \\
hermanastro & 12,7 & 2,7 & 40 & 19 & $1,124 \%$ & $0,563 \%$ \\
hermano mayor & 23,6 & 4,7 & 169 & 48 & $4,749 \%$ & $1,423 \%$ \\
hermano pequeño & 7,3 & 0,2 & 58 & 2 & $1,63 \%$ & $0,059 \%$ \\
mujer mayor & 1,1 & 8,4 & 13 & 68 & $0,365 \%$ & $1,779 \%$ \\
\hline
\end{tabular}

Tabla 4. Palabras clave que remiten a fantasías con personas mayores o a deseos incestuosos

Si observamos la tabla 4, notamos que hombre maduro es más frecuente en el subcorpus gay (f. p. m. I3,2 en IIo documentos) que mujer mayor ${ }^{10}$ en el lésbico (f. p. m. 8,4 en 68 textos). Asimismo, las palabras clave de este grupo se han detectado prevalentemente en la forma masculina y en el subcorpus gay, aunque las correspondientes formas femeninas aparezcan en los relatos lésbicos, sin prominencia de palabras clave. Si bien las keywords de la tabla 4 no se emplean siempre en el contexto de una fantasía sexual explícita, la observación de sus pautas colocacionales parece indicar que son precisamente los gais los que más sueñan con una pareja sexual más madura, observación de signo opuesto respecto a las conclusiones a las que llega Baker (2005:

\footnotetext{
Io Mujer madura aparece solo en 23 documentos del subcorpus lésbico (f. p. m. I,95), un número por debajo del umbral mínimo de textos (25) que fijamos al principio para tomar en consideración una palabra clave (véase 『2).
} 
I70), quien afirma que "what is happening in the lesbian texts [...] suggests two things: first that age differences are noted more often in these texts, and second, they are expressed in terms of one person being older, rather than younger than the other".

Asimismo, según el mencionado autor, en las narraciones eróticas la referencia a la edad suele funcionar como índice de experiencia, sabiduría o de iniciación de un personaje en una relación sexual. En nuestro corpus de estudio, esto es así principalmente en los cuentos sáficos, donde las mujeres mayores, expertas y poderosas, ofrecen a las jóvenes una garantía añadida de seguridad (II, I2). En los cuentos gay, en cambio, los hombres maduros, a menudo barrigudos, velludos, recios y activos, son más bien el objeto de pulsiones incestuosas $(8$, Io) o de fantasías muy explícitas de sumisión sexual (9):

(8) El mono azul del granjero descansaba por debajo de sus rodillas, dándole por fin al muchacho una visión completa del cuerpo desnudo de su padrastro. Juan imprimía a su rabo la misma velocidad que el hombre le estaba dando al suyo, ...cuando la voz del hombre lo devolvió a la realidad: ¿Se puede saber qué haces ahí pajeándote mientras me espías?

(9) Como bien sabéis mis preferencias son los hombres maduros activos... muy maduros, maduros activos que buscan un pasivo que les satisfaga, maduros que desean un pasivo y a ser posible sumiso, sin que tenga pluma o sean afeminados, maduros que buscan una buena putita que preñar.

(Io) Desde el día que te conocí, desde el día en que nuestros padres nos presentaron, estoy enamorado de ti Daniel... Se acercó a mí para besarme. Sí, besarme en los labios. No podía creerlo. - Pero...tú tienes novia... y somos hermanastros ... - Solo es una fachada...Ella lo sabe, solo es para que mi padre no lo sepa, ni él ni nadie.

(II) Soy una persona muy divertida, ando tirando chistes y me río todo el día. Para mi suerte, tiendo a ser del gusto de las mujeres mayores y como a mí me encantan... jah, sí! A todo esto, soy lesbiana.

(I2) Siempre me dije que más adelante habría tiempo para el amor y si este aún no había llegado a mi vida era porque aún no me correspondía vivirlo. Todo hasta que la conocí a ella, Raquel Mendieta, una mujer mayor de 35 años casada con un importante empresario del cual pensaba divorciarse.

Una posible explicación psicoanalítica de la elevada frecuencia, en los relatos masculinos, de fantasías de sumisión y de pulsiones incestuosas puede quizás rastrearse en el conocido caso clínico estudiado por Sigmund Freud (I970 [1955a]), el Hombre de los Lobos (Der Wolfsmann), donde se analiza la fijación afectiva del niño hacia el padre, fruto de un conflicto edípico no resuelto, que se manifiesta en tres aspiraciones sexuales que tienen como meta al padre: 
Haber nacido del padre, ser satisfecho sexualmente por él, parirle un hijo, y hacerlo renunciando a su virilidad y en el lenguaje del erotismo anal. El hijo no quiere trasmutar su sexo por el sexo opuesto, sino que desea tener también los atributos procreativos de la mujer. No hay una rivalidad del hijo con el padre ligada a la fantasía de incesto con la madre, sino más bien un antagonismo entre padre e hijo como reflejo de una situación de oposición homosexual, en el sentido de la lucha violenta entre hombres para dominarse uno a otro y poseerse uno al otro (Torres Arias, I992: 338).

La renuncia a la virilidad del homosexual pasivo sumiso y su deseo de poseer genitales femeninos se aprecia claramente en el fragmento (9), donde la voz narrativa, recurriendo al "lenguaje del erotismo anal", se autoidentifica como buena putita que preñar. Asimismo, según Freud, la predisposición a la homosexualidad masculina también podría deberse a una vinculación erótica-incestuosa del hijo con la madre, favorecida por la hiperternura materna (es decir, la seducción de esta sobre el niño) y sustentada por la figura de un padre ausente, que llevaría al hijo varón a identificarse con ella y a transformar su propia persona en el modelo de objeto de amor, optando por una sexualidad de tipo narcisista. Por último, cuando el padre es duro, violento o cruel, también el superyó del hijo tiende a adoptar esas cualidades volviéndose sádico, mientras que el yo deviene masoquista, a saber, femeninamente pasivo en el fondo ${ }^{\text {II }}$ y propenso a desempeñar un papel sumiso, máxime con un hombre mayor y corpulento que evoca la imago del padre protector. El objeto de dicha pulsión masoquista no ha de ser necesariamente el padre, sino que puede ser también el hermano mayor ( $u$ otras figuras equivalentes como el hermanastro, ej. Io), que representaría una duplicación narcisista del yo del sujeto en el mundo externo (Fagioli, I965).

También la homosexualidad femenina, según Freud (I976 [i955b]), tendría su origen en la etapa edípica del desarrollo psicosexual: frustrada por la envidia del pene, a partir del descubrimiento de su "castración" (la ausencia del órgano masculino, descubierto en los varones), la niña acabaría renunciando al deseo del pene para sustituirlo por el deseo de tener un hijo y elige al padre como objeto del amor. Como es la madre la que tiene relaciones sexuales con el padre, la madre pasa a ser objeto de los celos de la niña: al sentirse decepcionada y traicionada, se identifica con el padre y, a la vez, intensifica el

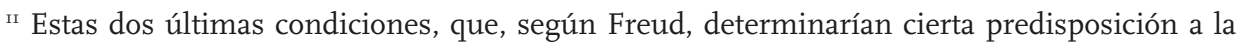
homosexualidad masculina, se analizan en detalle en Un recuerdo infantil de Leonardo Da Vinci (Freud i976 [ı10]) y en Dostoievski y el Parricidio (Freud I976 [196rb]).
} 
amor a la madre para compensar su odio hacia ella. Como no la puede tener como amante, busca un sustituto femenino con el que encariñarse, volviéndose homosexual. De esta manera, le "cede el paso" a la madre en su relación con los hombres y, al hacerlo, acaba reconciliándose con ella (Gesuè, 20I8). Así pues, el deseo erótico de una joven lesbiana por una mujer mayor, exitosa y protectora (II, I2) acabaría siendo, en última instancia, una manera para recuperar el amor maternal.

\subsection{Los personajes y la exasperación de sus rasgos de género}

La forma más inmediata para caracterizar a los personajes masculinos y femeninos de las narraciones eróticas es la elección de los nombres propios, signos lingüísticos dotados de un evidente valor indexical. Como ya señaló Scott (1999), una de las características más llamativas de una lista de palabras clave es la preponderancia de nombres propios y, a este respecto, los dos subcorpus de estudio no constituyen una excepción. A continuación, se presentan las tablas 5 y 6 , que contienen los primeros 30 lemas clave de ambos subcorpus de relatos:

\begin{tabular}{|c|c|c|c|c|c|c|c|c|}
\hline & \multirow[t]{2}{*}{ Lema } & \multicolumn{2}{|c|}{$\begin{array}{l}\text { Frec. por millón } \\
\text { (f.p.m.) }\end{array}$} & \multicolumn{2}{|c|}{ N. documentos } & \multicolumn{2}{|c|}{ Relative DOCF } & \multirow[t]{2}{*}{ Punt. } \\
\hline & & Enfoque & Referencia & Enfoque & Referencia & Enfoque & Referencia & \\
\hline 1 & polla & 1934,4 & 12,6 & 1907 & 57 & $53,582 \%$ & $1,69 \%$ & 142,8 \\
\hline 2 & semen & 401,5 & 2,5 & 1469 & 21 & $41,276 \%$ & $0,623 \%$ & 113,6 \\
\hline 3 & verga & 1013,1 & 8,1 & 1211 & 38 & $34,026 \%$ & $1,127 \%$ & 110,9 \\
\hline 4 & rabo & 250,3 & 1,8 & 769 & 12 & $21,607 \%$ & $0,356 \%$ & 90,4 \\
\hline 5 & ojete & 85,4 & 0,2 & 391 & 2 & $10,986 \%$ & $0,059 \%$ & 73,9 \\
\hline 6 & Edson & 72,4 & o & 21 & o & $0,59 \%$ & ०\% & 73,4 \\
\hline 7 & glande & 209,1 & 1,9 & 1021 & 13 & $28,688 \%$ & $0,385 \%$ & 73,3 \\
\hline 8 & cipote & 63,5 & o & 212 & o & $5,957 \%$ & ०\% & 64,5 \\
\hline 9 & calzoncillo & 150,7 & 1,4 & 789 & 11 & $22,169 \%$ & $0,326 \%$ & 64,4 \\
\hline 10 & Ian & 62,5 & o & 45 & O & $1,264 \%$ & ०\% & 63,5 \\
\hline 11 & Cristián & 58,1 & O & 20 & O & $0,562 \%$ & ०\% & 59,1 \\
\hline 12 & capullo & 147,3 & 1,6 & 716 & 18 & $20,118 \%$ & $0,534 \%$ & 56,8 \\
\hline 13 & slip & 75,1 & 0,4 & 362 & 3 & 10,17\% & $0,089 \%$ & 53,4 \\
\hline 14 & empalmar & 79,6 & 0,5 & 513 & 6 & $14,92 \%$ & $0,178 \%$ & 53,4 \\
\hline 15 & lefa & 65,4 & 0,3 & 423 & 3 & $11,885 \%$ & $0,089 \%$ & 49,6 \\
\hline 16 & precum & 47,5 & o & 342 & o & $9,609 \%$ & ०\% & 48,5 \\
\hline
\end{tabular}




\begin{tabular}{|c|c|c|c|c|c|c|c|c|}
\hline & \multirow[t]{2}{*}{ Lema } & \multicolumn{2}{|c|}{$\begin{array}{l}\text { Frec. por millón } \\
\text { (f.p.m.) }\end{array}$} & \multicolumn{2}{|c|}{ N. documentos } & \multicolumn{2}{|c|}{ Relative DOCF } & \multirow[t]{2}{*}{ Punt. } \\
\hline & & Enfoque & Referencia & Enfoque & Referencia & Enfoque & Referencia & \\
\hline 17 & mamada & 148,6 & 2,1 & 969 & 21 & $27,227 \%$ & $0,623 \%$ & 47,9 \\
\hline 18 & Tulio & 44,7 & 0 & 27 & 0 & $0,759 \%$ & ०\% & 45,7 \\
\hline 19 & maricón & 89,9 & 1 & 406 & 10 & $11,408 \%$ & $0,296 \%$ & 45 \\
\hline 20 & Ethan & 48,7 & 0,2 & 27 & 2 & $0,759 \%$ & $0,059 \%$ & 42,5 \\
\hline 21 & tetilla & 51,6 & 0,3 & 354 & 3 & $9,947 \%$ & $0,089 \%$ & 41,9 \\
\hline 22 & follada & 74,5 & 0,9 & 477 & 10 & $13,403 \%$ & $0,296 \%$ & 39,1 \\
\hline 23 & chaval & 157,4 & 3,2 & 630 & 28 & $17,702 \%$ & $0,83 \%$ & 37,5 \\
\hline 24 & Kilian & 36,2 & 0 & 23 & 0 & $0,646 \%$ & ०\% & 37,2 \\
\hline 25 & macho & 236,8 & 5,7 & 1010 & 51 & $28,379 \%$ & $1,512 \%$ & 35,6 \\
\hline 26 & Fabián & 33,7 & o & 40 & 0 & $1,124 \%$ & ०\% & 34,7 \\
\hline 27 & Sergei & 36,5 & 0,1 & 14 & 1 & $0,393 \%$ & $0,03 \%$ & 34,5 \\
\hline 28 & Borja & 33 & 0 & 65 & 0 & $1,826 \%$ & ०\% & 34 \\
\hline 29 & Evans & 32,2 & 0 & 61 & 0 & $1,714 \%$ & ०\% & 33,2 \\
\hline 30 & Amadeo & 37,8 & 0,2 & 35 & 1 & $0,983 \%$ & $0,03 \%$ & 33,1 \\
\hline
\end{tabular}

Tabla 5. Primeros 30 lemas clave del subcorpus de relatos gais. Referencia: relatos lésbicos

\begin{tabular}{|c|c|c|c|c|c|c|c|c|}
\hline & \multirow[t]{2}{*}{ Lema } & \multicolumn{2}{|c|}{$\begin{array}{l}\text { Frec. por millón } \\
\text { (f.p.m.) }\end{array}$} & \multicolumn{2}{|c|}{ N. documentos } & \multicolumn{2}{|c|}{ Relative DOCF } & \multirow{3}{*}{$\begin{array}{l}\text { Punt. } \\
500\end{array}$} \\
\hline & & Enfoque & Referencia & Enfoque & Referencia & Enfoque & Referencia & \\
\hline 1 & Xena & 499 & o & 77 & o & $2,283 \%$ & ०\% & \\
\hline 2 & Gabrielle & 467,8 & 0,1 & 87 & 1 & $2,579 \%$ & $0,028 \%$ & 431,5 \\
\hline 3 & Sophia & 218,6 & O & 35 & o & $1,038 \%$ & ०\% & 219,6 \\
\hline 4 & Alely & 170,6 & o & 16 & o & $0,474 \%$ & ०\% & 171,6 \\
\hline 5 & Kiara & 165 & o & 31 & o & $0,919 \%$ & ०\% & 166 \\
\hline 6 & Emma & 351,9 & 1,9 & 64 & 5 & $1,897 \%$ & $0,14 \%$ & 121,6 \\
\hline 7 & Isabella & 106,9 & O & 75 & o & $2,224 \%$ & ०\% & 107,9 \\
\hline 8 & Zoe & 93,9 & O & 16 & o & $0,474 \%$ & ०\% & 94,9 \\
\hline 9 & Sophie & 90,9 & o & 61 & o & $1,808 \%$ & ०\% & 91,9 \\
\hline 10 & Valeria & 190,1 & 1,3 & 103 & 4 & $3,054 \%$ & $0,112 \%$ & 83,2 \\
\hline 11 & Scarlet & 82,2 & o & 39 & o & $1,156 \%$ & ०\% & 83,2 \\
\hline 12 & guerrera & 131,6 & 0,7 & 86 & 6 & $2,55 \%$ & $0,169 \%$ & 78,4 \\
\hline 13 & Bardo & 171,5 & 1,2 & 59 & 2 & $1,749 \%$ & $0,056 \%$ & 78 \\
\hline 14 & Xenia & 76 & o & 15 & o & $0,445 \%$ & ०\% & 77 \\
\hline 15 & Any & 94,6 & 0,3 & 67 & 3 & $1,986 \%$ & $0,084 \%$ & 75,9 \\
\hline
\end{tabular}


"La princesa guerrera enarcó una ceja, mientras el macarra bamboleaba..."

\begin{tabular}{|c|c|c|c|c|c|c|c|c|}
\hline & \multirow[t]{2}{*}{ Lema } & \multicolumn{2}{|c|}{$\begin{array}{l}\text { Frec. por millón } \\
\text { (f.p.m.) }\end{array}$} & \multicolumn{2}{|c|}{ N. documentos } & \multicolumn{2}{|c|}{ Relative DOCF } & \multirow[t]{2}{*}{ Punt. } \\
\hline & & Enfoque & Referencia & Enfoque & Referencia & Enfoque & Referencia & \\
\hline 16 & Fernanda & 240,6 & 2,2 & 188 & 4 & $5,574 \%$ & $0,112 \%$ & 74,4 \\
\hline 17 & Gabriela & 140,7 & 1 & 127 & 4 & $3,765 \%$ & $0,112 \%$ & 72,6 \\
\hline 18 & Desi & 80,3 & 0,2 & 10 & 1 & $0,296 \%$ & $0,028 \%$ & 69,3 \\
\hline 19 & Allison & 67,2 & 0 & 19 & 0 & $0,563 \%$ & ०\% & 68,2 \\
\hline 20 & Emily & 92 & 0,4 & 32 & 2 & $0,949 \%$ & $0,056 \%$ & 64,9 \\
\hline 21 & Paige & 60,7 & 0 & 25 & ○ & $0,741 \%$ & ०\% & 61,7 \\
\hline 22 & Paola & 81,8 & 0,3 & 85 & 4 & $2,52 \%$ & $0,112 \%$ & 61,6 \\
\hline 23 & Tessa & 57,3 & 0 & 22 & o & $0,652 \%$ & ०\% & 58,3 \\
\hline 24 & Sidney & 55,2 & 0 & 16 & o & $0,474 \%$ & ०\% & 56,2 \\
\hline 25 & Jaaz & 52 & 0 & 1 & 0 & $0,03 \%$ & ०\% & 53 \\
\hline 26 & Ashly & 50,1 & 0 & 32 & 0 & $0,949 \%$ & ०\% & 51,1 \\
\hline 27 & Alein & 48,6 & 0 & 8 & 0 & $0,237 \%$ & ०\% & 49,6 \\
\hline 28 & Emilia & 64,1 & 0,3 & 20 & 2 & $0,593 \%$ & $0,056 \%$ & 48,4 \\
\hline 29 & Mel & 47,3 & 0 & 39 & 0 & $1,156 \%$ & ०\% & 48,3 \\
\hline 30 & Mafer & 46,4 & 0 & 18 & 0 & $0,534 \%$ & ०\% & 47,4 \\
\hline
\end{tabular}

Tabla 6. Primeros 30 lemas clave del subcorpus de relatos lésbicos. Referencia: relatos gais

Notamos que la tabla 5 contiene, además de los previsibles ítems de género marcado (genitales y fluidos masculinos, prendas de vestir de hombre, sustantivos y verbos que indican prácticas sexuales, los antónimos maricón/ macho etc.), once nombres propios masculinos, no del todo "tradicionales" en español, como Edson, Ian, Etham, Kilian, Sergei o Evans, que añaden un rasgo "exótico" a varios protagonistas. Examinando con más detalle las demás palabras clave en los relatos gay, descubrimos que esa misma tendencia al exotismo se ve amplificada por otros nombres propios como Abdullah, Karim, Yasin, Ousmane, Omar, Mustafá, etc. o por la prominencia de adjetivos como árabe, moro, rumano, turco o búlgaro, que, ahondando en estereotipos culturales afianzados, tienden a construir el modelo de un amante masculino muy varonil, fogoso y dominante:

(13) Sus manos [magreaban] mis nalgas, dándoles pellizcos y azotes o tirando de mis pezones hasta hacerme daño. El árabe abriéndose puso una de sus piernas encima de mis hombros en señal de victoria y total dominio sobre mí.

Si ahora nos fijamos en la tabla 6 , notamos a simple vista que todas las primeras 30 palabras clave de los cuentos lésbicos son nombres de mujeres y 
que no destaca ningún otro elemento característico del género, como podría ser la alusión a la lencería o a los genitales femeninos. Observando más de cerca, notamos que los dos primeros ítems son Xena y Gabrielle, conocidas protagonistas de una serie estadounidense -titulada Xena: la princesa guerrera- que fue muy popular y se convirtió en uno de los primeros referentes televisivos para el empoderamiento del colectivo de lesbianas. Ambientada en la antigua Grecia, la serie original tenía un cariz ligeramente sáfico, sin llegar a ser nunca explícito o de mal gusto, y narraba las aventuras de la princesa Xena (una especie de alter ego femenino de Alejandro Magno), Señora Conquistadora de la Hélade, y de su inseparable amiga guerrera Gabrielle. Es evidente que los 77 ficheros en los que aparece el ítem Xena son versiones lésbicas amateur ${ }^{12}$ de los episodios de la referida serie y constituyen ejemplos del género fanfiction de temática homosexual. Estos nombres femeninos funcionan como expresiones indexicales que remiten a la antigua Grecia, patria de Safo de Mitilene y dimensión idílica del amor homosexual más noble. Dichas relaciones paradigmáticas de sentido se ven reforzadas por una retahíla de otras palabras clave que son nombres propios griegos, femeninos (Afrodita, Casandra, Hécuba, Perséfone, Selene, Dímitra, Zoe, etc.) y masculinos (Pericles, Heródoto, Homero, etc.). Así pues, el contraste entre los nombres propios clave en las dos categorías de relatos nos revela, de entrada, una caracterización antagónica de los protagonistas del imaginario erótico de gais y lesbianas: hombres carnales, apasionados y dionisíacos los primeros; mujeres más bien idealizadas, íntimas y apolíneas las segundas. Se trata, obviamente, de los dos extremos de un continuum en la construcción del deseo homoerótico, ya que también en el corpus lésbico asoman, de vez en cuando, figuras femeninas más "periféricas", p. ej., la protagonista de algunos cuentos que se llama Buch (f. p. m. 5, en 5 documentos), a saber, chica ruda (f. p. m. 2,5, en I 8 textos).

Desde el punto de vista sociolingüístico, es en las narraciones gais donde predominan los rasgos típicos de ambientes populares o marginales (de ahí, p. ej., que los ítems puta madre u hostia sean clave en el subcorpus gay y no en el lésbico), mientras que las narraciones lésbicas no suelen ostentar vulgarismos excesivos y las keywords describen a las protagonistas con epítetos ennoblecedores como guerrera, capitana, heroína, ejecutiva, profesora, doctora, amazona, etc. La posible explicación de esta asimetría reside en la tendencia

\footnotetext{
${ }^{12}$ Es interesante notar que la mayoría de estos textos son, en realidad, traducciones (supuestamente del inglés americano al español), lo cual evidencia el papel clave de la traducción en la circulación de modelos eróticos de referencia, incluso en la comunidad LGTBI.
} 
de los cuentos homoeróticos a extremar los rasgos de género, al hilo de lo que observa Baker (2005: I63-64), al definir como hyper-gendered a los protagonistas de este tipo de relatos: "men are extremely masculine and women are extremely feminine". Este discurso, que tiende a "encasillar" el deseo erótico dentro de moldes socioculturales prefijados, deja muy poco espacio a la manifestación de otras masculinidades o femineidades alternativas:

\begin{tabular}{|c|c|c|c|c|c|c|}
\hline \multirow[t]{2}{*}{ Palabra clave } & \multicolumn{2}{|c|}{$\begin{array}{l}\text { Frecuencia normalizada por } \\
\text { millón }\end{array}$} & \multicolumn{2}{|c|}{$\begin{array}{l}\text { N. de documentos que con- } \\
\text { tienen la palabra clave }\end{array}$} & \multicolumn{2}{|c|}{$\begin{array}{l}\text { \% documentos que con- } \\
\text { tienen la palabra clave } \\
\text { (Relative DOCF) }\end{array}$} \\
\hline & T. gay & T. lésbicos & T. gay & T. lésbicos & T. gay & T. lésbicos \\
\hline macho & 236,8 & 5,7 & 1010 & 51 & $28,379 \%$ & $1,512 \%$ \\
\hline macho dominante & 2,5 & 0 & 27 & O & $0,759 \%$ & ०\% \\
\hline macho alfa & 4,3 & 0,3 & 45 & 4 & $1,264 \%$ & $0,119 \%$ \\
\hline heteros & 7,6 & 1,3 & 72 & 14 & $2,023 \%$ & $0,415 \%$ \\
\hline macarra & 4,8 & 0,3 & 36 & 3 & $1,012 \%$ & $0,089 \%$ \\
\hline camionero & 17,6 & 0,7 & 28 & 6 & $0,787 \%$ & $0,178 \%$ \\
\hline hombría & 9,2 & 0,4 & 91 & 5 & $2,557 \%$ & $0,148 \%$ \\
\hline hombre de verdad & 3,1 & 0,7 & 32 & 6 & $0,899 \%$ & $0,178 \%$ \\
\hline virilidad & 12,8 & 0,4 & 125 & 4 & $3,512 \%$ & $0,119 \%$ \\
\hline manazas & 6,6 & 0,1 & 63 & 1 & $1,77 \%$ & $0,03 \%$ \\
\hline toro & 18,4 & 2,4 & 163 & 21 & $4,58 \%$ & $0,623 \%$ \\
\hline semental & 23,2 & 1 & 175 & 11 & $4,917 \%$ & $0,326 \%$ \\
\hline viril & 20,6 & 0,8 & 189 & 9 & $5,31 \%$ & $0,267 \%$ \\
\hline peludo & 54,2 & 3,8 & 401 & 35 & $11,267 \%$ & $1,038 \%$ \\
\hline musculado & 13,5 & 0,3 & 134 & 3 & $3,765 \%$ & $0,089 \%$ \\
\hline varonil & 24,5 & 2,4 & 233 & 28 & $6,547 \%$ & $0,83 \%$ \\
\hline mulato & 10,5 & 0 & 43 & $\mathrm{O}$ & $1,208 \%$ & $0 \%$ \\
\hline pasivo & 45,3 & 2,7 & 326 & 30 & $9,16 \%$ & $0,889 \%$ \\
\hline princesa guerrera & 0 & 5,6 & O & 32 & ०\% & $0,949 \%$ \\
\hline niña pequeña & 1 & 12,7 & 11 & 132 & $0,309 \%$ & $3,913 \%$ \\
\hline alma gemela & 0,7 & 9,2 & 8 & 60 & $0,225 \%$ & $1,779 \%$ \\
\hline mujer de mi vida & 0,2 & 6 & 2 & 65 & $0,056 \%$ & $1,927 \%$ \\
\hline amor de mi vida & 5,2 & 16,1 & 53 & 151 & $1,489 \%$ & $4,477 \%$ \\
\hline amor platónico & 1,5 & 2,7 & 16 & 30 & $0,45 \%$ & $0,889 \%$ \\
\hline amor eterno & 1,8 & 3,1 & 20 & 31 & $0,562 \%$ & $0,919 \%$ \\
\hline chica hermosa & 0,1 & 4,8 & 1 & 40 & $0,028 \%$ & $1,186 \%$ \\
\hline niña hermosa & 0,1 & 5,3 & 1 & 45 & $0,028 \%$ & $1,334 \%$ \\
\hline mujer alta & 0,2 & 7 & 2 & 48 & $0,056 \%$ & $1,423 \%$ \\
\hline amazona & 0,4 & 54,3 & 5 & 54 & $0,14 \%$ & $1,601 \%$ \\
\hline enamorada & 12,4 & 48,3 & 131 & 418 & $3,681 \%$ & $12,393 \%$ \\
\hline maternal & 0,4 & 4,2 & 5 & 42 & $0,14 \%$ & $1,245 \%$ \\
\hline mirada cómplice & 1,2 & 3 & 14 & 32 & $0,949 \%$ & $0,534 \%$ \\
\hline mirada asesina & 2,1 & 4,9 & 20 & 51 & $0,562 \%$ & $1,512 \%$ \\
\hline sonrisa cómplice & 1,6 & 3,4 & 19 & 35 & $1,038 \%$ & $0,393 \%$ \\
\hline sonrisa burlona & 2,8 & 4,7 & 29 & 44 & $0,815 \%$ & $1,304 \%$ \\
\hline sonrisa hermosa & 0,3 & 2,3 & 3 & 25 & $0,741 \%$ & $0,084 \%$ \\
\hline sonrisa enorme & 0,3 & 2,5 & 4 & 29 & $0,112 \%$ & $0,86 \%$ \\
\hline beso dulce & 0,5 & 3,5 & 5 & 39 & $0,14 \%$ & $1,156 \%$ \\
\hline ojito & 4,2 & 26,6 & 46 & 222 & $1,293 \%$ & $6,582 \%$ \\
\hline
\end{tabular}

Tabla 7. Ejemplos de palabras clave que extreman los rasgos de género en los dos subcorpus 
El espacio del que disponemos no permite realizar un análisis pormenorizado de concordancias de todas las palabras claves contenidas en la tabla 7; valgan los ejemplos siguientes para poner de manifiesto que, en el imaginario gay, la pareja sexual ideal (hombre de verdad) suele ser el arquetipo del macho alfa, dominante, fuerte y peludo, a veces mulato, de clase social media-baja (macarra o cani), frecuentemente "animalizado", como toro o semental:

(I4) Era un completo macho alfa y su gran pene se convulsionaba, lanzando unos chorrazos de leche increíbles, que repartió como buen hombre entre nuestras lenguas y bocas, sedientas de semen de pollón.

(I5) Llevaba el pelo muy rapado y tenía una barba de dos días muy negra. Se llamaba Pedro y resultó ser un cani, que es así como les llaman a los macarras chandaleros por allí abajo.

(i6) Me folló lentamente al comienzo, luego fue subiendo su intensidad hasta que no pudo aguantar más y se corrió como un auténtico semental, [...] al final de su corrida, me clavó tres estocadas bestiales en un punto de mi interior que hizo que me corriera como si nunca lo hubiera hecho.

(I7) Es un colega de mi equipo de Rugby. Un torete follador. De vez en cuando nos montamos fiestecillas con alguna maricona como tú o alguna puta. No te vamos a hacer nada, solo queremos que nos la comas. Somos dos machos heteros y estoy disfrutando tanto que es una pena que te vayas. Es tu oportunidad, explicó.

Como puede observarse, el sueño erótico más salvaje en los relatos gay es que uno o más machos heteros resulten sexualmente asequibles (I7), aunque, en algunos casos, el mito del "macho casado o con novia" se pone en entredicho desde la propia perspectiva que alimenta al machismo gay. Al observar algunas concordancias de hetero, macarra y pasivo, p. ej., se detecta un ejercicio de ironía que, paradójicamente, acaba afianzando el discurso de la homosexualidad encubierta, a la que aludíamos en $\ 2$. I, el desprecio al pasivo amanerado (ipor los propios protagonistas pasivos!) y la creencia generalizada de que los auténticos machos activos son muy pocos:

(I8) Es un macarra moreno agitanado, pelo muy corto, ojos marrones, delgado de cuerpo y una verga de $25 \mathrm{~cm}$ la cual sabe muy bien utilizar. Pero a él lo que le gusta... con lo que disfruta el cabrón... es ponerse unas braguitas de su mujer y que lo trate como una puta traganabos.

(i9) ¡Algunos de machos solo tienen la testosterona que les hace crecer esa pelambrera! ¡Pero, a la hora de la verdad, son más pasivos que yo!

A la manera de los personajes del artista homoerótico finlandés Tom of Finland, los protagonistas de las ensoñaciones gais suelen tener atributos de 
desmedido tamaño, de ahí que el adjetivo clave monstruoso u otros adjetivos intensificadores equivalentes (enorme, gordo, grueso, tremendo, inmenso, descomunal, etc.) se coliguen casi sistemáticamente con sustantivos clave como polla, pene, miembro, verga, palo de carne, bicho, bulto, rabo, poronga, pija y que los lemas referidos a los genitales masculinos presenten a menudo sufijación elativizadora (rabazo, pollón, paquetón, vergajo). En una clara exhibición de machismo, este amante ideal hace alarde de sus atributos viriles, que se coligan a menudo con el verbo clave bambolear/se (f. p. m. 5,9 vs. 0,9; en 62 relatos gais y 9 lésbicos):

(20) El paquete, bamboleando bajo el pantalón de faena cuando andaba por el monte, hacía que mi deseo chorreara.

(2I) Se fue rumbo a su cuarto y salió con la toalla al hombro y en pelotas, bamboleando el pene y esos enormes coyoles que tiene por huevos.

Se observa también cierta recursividad en la práctica de dominación amo-esclavo que el macho dominante establece con el pasivo, frecuentemente feminizado y sometido a un trato verbal y físico humillante (adjetivo clave con una f. p. m. de 5,7 vs. o,9, detectado en 59 textos gais y en io lésbicos). Asimismo, los compuestos sintagmáticos sesión de sexo y sexo salvaje, con diferencias prevalentes en las narraciones gais, apuntan a prácticas de "sexo duro", llevadas a cabo de forma mecánica y violenta (Baker, 2005: I7I-72), y comparten la misma prosodia evaluativa que otras palabras clave como arremeter, embestir, taladrar, empotrar, empalar, bombear, arma, trabuco, porra:

(22) Yo soy un macho y tú eres un maricón, y los maricas como tú estáis para servir a los machos como yo. Antes de terminar la frase, el perro [que era yo] ya se había comido unos cuantos azotes.

(23) Aprieto los labios en torno a su nabo y echo la cabeza hacia adelante y hacia atrás. Al principio, se quejaba por los dientes, pero al momento sólo jadea y me suelta frases humillantes que me sientan fatal, pero que aprendo a ignorar.

(24) Gemía sin parar y bufaba como un semental empotrando a una yegüa.

(25) No sé cómo explicarlo, noté cuando su [verga] entró y vi estrellas. Luego ya todo era sudor y sexo, sexo salvaje y duro: me penetraba con vehemencia, yo solo gemía como puta barata entregada al placer.

Al comentar las frecuentes sesiones de dominación entre gais que entrañan dolor físico (25), Baker (2005: I72) señala que "enduring pain (particularly as the passive partner during anal sex) is a way that masculine identity can be sustained during a sexual act which is normally associated with taking a feminine/passive role". Para respaldar esta tesis, citando a Zeeland (I996), 
Baker menciona el caso de los marines norteamericanos, quienes consideran que ser penetrados es un auténtico test de resistencia masculina, que le otorga al pasivo un mayor poder efectivo. Aunque las concordancias de los ítems de la tabla 3 revelen, en el subcorpus gay, una clara prevalencia de fantasías de dominación, es cierto que, en casos esporádicos, los estereotipos del macho dominante y del pasivo humillado se desmienten. Se reconoce, p. ej., que el pasivo puede llegar a ser el auténtico dominante (26), que se puede disfrutar el rol pasivo de hombre a hombre, sin sumisión ni insultos y que el maltrato verbal o la feminización del pasivo pueden resultar molestos y apagar la libido (27), lo cual abre en el deseo homoerótico un resquicio de autonomía con respecto al modelo heteronormativo:

(26) Muchas personas relacionan el individuo dominante al tipo que es activo. Mientras que el pasivo es como el sumiso. Pero eso es no más que un estereotipo machista, basado en parejas heterosexuales. [...] Yo, personalmente, soy activo la gran mayoría de veces y me gusta serlo. El rubio, por su lado, es pasivo. [...] En muchas ocasiones, el que domina de verdad es el rubio.

(27) [Su mensaje ponía:] "seguro que gozarás como la perra caliente que eres", incluía sus datos, para que lo llamara, y una foto. No era lo que andaba buscando, tenía un poco de tripa y era demasiado musculado y peludo para mi gusto, tipo oso. Además, no me gusta que me traten de perra ni que me mujereen.

Tras analizar los rasgos masculinos preponderantes en el imaginario erótico gay, es suficiente ahora que nos fijemos en las palabras clave de la tabla 7 que prevalecen en las narraciones lésbicas para darnos cuenta de que el ideal femenino prototípico que emerge de estos relatos es una figura idealizada, valiente y noble (una princesa guerrera o una amazona), personificada en la señora conquistadora Xena. La observación de las concordancias de las palabras clave que remiten a este personaje nos confirma que se trata de una heroína protectora, despiadada en la lucha contra los enemigos de su gente y tierna y comprensiva con sus allegados y esclavos, perfecto sustituto de la figura materna con la que el ello lésbico, según Freud, aspiraría a reconciliarse (『2.I). Obsérvese, p. ej., este fragmento de diálogo entre Xena y Gabrielle, interpretable como manifestación de un posible síndrome de abandono y del miedo a perder la figura fuerte y protectora del cuidador (caregiver):

(28) Tengo miedo, Xena -declaró Gabrielle simplemente. Me volví para mirarla, confusa. -Gabrielle, ¿de qué tienes miedo... ¿de mí? -No de ti... yo... Xena, ¿qué será de mí cuando ya no me desees? -soltó de sopetón, con los ojos llenos de lágrimas. -¿Qué? -me quedé sin habla. ¿Acaso había hecho algo para ha- 
cerle creer que ésa era mi intención? Gabrielle se echó a llorar sollozando. - ¿Qué será de mí cuando ya no te interese, qué ocurrirá si me vendes a otro amo?

Este deseo de protección y ternura parece respaldado también por el adjetivo clave maternal (f. p. m. 4,2 vs. 0,4 ; en 42 textos lésbicos y 5 gais):

(29) De a poco aflojaron sus nervios, las piernas de Giuliana dejaron de temblar, Beatriz la abrazaba y la acurrucaba en su pecho, con una ternura casi maternal, podría decirse, mirándose intenso a los ojos. - ¿Te dije que sos muy bonita? -No, creo que no. -Bueno, ahora te lo digo. Sos muy bonita, Giuli.

Este prototipo de mujer, hambrienta de ternura y propensa a las relaciones platónicas (30), aspira a encontrar el amor de su vida (3I). En términos contrastivos, emerge, por tanto, un ego lésbico más "egosintónico" y en busca de afectividad, que anhela la complicidad emocional y que no se limita a la pura genitalidad compulsiva, como en las fantasías eróticas masculinas:

(30) Al siguiente día, me preparé para irme a clases, de cierta manera me sentía rara, ya que la última vez que estuve en la universidad y en clases, Karen solamente era un amor platónico, y ahora de una u otra manera había algo más.

(3I) Esta tarde para mí fue la más especial e inolvidable de mi vida, el amor de mi vida está a mi lado, me acabo de entregar a ella con todo mi amor y ella a mí, me siento realmente feliz, miro su carita y me lleno de ternura, como ella dijo valieron la pena los años de lucha y sufrimiento.

Asimismo, cuando la mujer ideal de las narraciones lésbicas no es una heroína guerrera sino una mujer más real, no suele presentar rasgos físicos femeninos provocativos o extremados, como revelan los términos sintagmáticos cuya base es mujer ( alta, de mi vida, mayor, menuda, hermosa, perfecta, morena, fuerte, rubia, madura, de pelo negro/corto/claro, etc.), y mantiene a menudo ademanes de niña pequeña (f. p. m. I2,7 vs. I; en I32 textos lésbicos y II gais), p. ej., la costumbre de hacer pucheros (f. p. m. 28,8 vs. 5; en 260 textos lésbicos y 5 I gais):

(32) Lucía: Me alegra ver que ya habéis arreglado las cosas. Ambas sonreímos, le cogí la mano y la besé. Yo: Es como una niña pequeña, no puede evitar meterse en líos.

(33) Se inclinó sobre ella y la besó dulcemente, viendo la excitación en su mirada. -He sido una novia muy mala -dijo haciendo pucherito. -No, yo lo he sido. 
La pasión y la complicidad entre mujeres suelen construirse y reforzarse a través de la mirada y ese íntimo contacto visual suele desencadenar la sonrisa. De hecho, en los relatos lésbicos la comunicación visual y las señales percibidas a través de los ojos parecen ser el mecanismo más poderoso que desencadena reacciones emocionales o verbales, como el deseo, el enfado o la cólera, según indican las concordancias de los ítems clave mirada cómplice, mirada asesina, sonrisa cómplice, sonrisa burlona, sonrisa hermosa y sonrisa enorme:

(34) Me senté con ellas y nos quedamos en silencio por un rato, ellas se daban miradas cómplices como en un lenguaje visual y por lo que veía parecía que se entendían.

(35) “¿Pero me quieres para siempre?”, le preguntó Dani mientras seguía clavando su mirada en Bea. "Sí, para siempre," le dijo ella acariciándole la frente a Dani. "Entonces, ¿me das un beso?", le dijo Dani con una sonrisa enorme.

La centralidad absoluta de la mirada y de los ojos en la comunicación amorosa entre lesbianas se refleja también en la palabra clave ojito, cuya frecuencia particularmente elevada parece deberse también al mayor uso de los derivados en ito (RAE, 2009: 643) y, en general, a la mayor productividad de la derivación apreciativa en el español americano (Lázaro Mora, I999: 4651), muy presente en los relatos sáficos, respecto al español peninsular:

(36) ¿ Princesita quieres ser formalmente mi novia? Sus ojitos se llenaron de alegría y una enorme sonrisa invadió su rostro pero de inmediato se borró y con miedo volvió a ver a su mamá y hermana.

Obviamente, entre las palabras clave gay no hay rastro del ítem ojito, mientras que resultan inusualmente frecuentes ojete (f. p. m.: 85,5 vs. 0,2; en 39I textos gay y en 2 lésbicos ) o las unidades metafóricas ojal (en la previsible acepción de ano, f. p. m.: 4,6 vs. o, en 44 textos gay y en ninguno lésbico), ojo del amor (f. p. m.: 2,8 vs. o; en 28 textos gais y en ninguno lésbico) y el americanismo orto (f. p. m.: 6,6 vs. 0,3 , en 46 cuentos gais y en 3 lésbicos), dato que amplía la brecha entre la fijación masculina con la penetración y la sexualidad más íntima de las mujeres lesbianas, alimentada a base de miradas, caricias y dulces besos.

Por último, otro interesante dato comparativo es la ausencia casi total de formas verbales entre las keywords de las narraciones lésbicas. Si en los relatos gais hemos detectado una plétora de verbos clave que construyen el encuentro sexual como una "sesión de sexo duro", en el subcorpus lésbico, en cambio, destacan solo, en la escala de puntuación, las formas verbales enarcar 
(las cejas), celar, desentender y murmurar. Así pues, el gesto que más parece caracterizar a las protagonistas de los relatos lésbicos es enarcar la/una ceja (puntuación 5), acción que puede expresar disconformidad, desconcierto o perplejidad frente al interlocutor y que, en general, es el epifenómeno de una pasión que se intenta controlar (p. ej., "Jane enarcó una ceja para acentuar aún más su desconcierto”). Inmediatamente después, el verbo más relevante en los relatos sáficos analizados es celar (puntuación 4,9), empleado en la acepción, poco frecuente en español peninsular, de "atender con esmero al cuidado y observación de la persona amada por tener celos" (RAE, 20I4). Los celos constituirían, por tanto, un rasgo distintivo muy característico de las narraciones sáficas, mientras que son casi irrelevantes en el imaginario erótico de los gais (p. ej.: "Es normal que [tu novia] te cele tanto, con un cuerpo como el tuyo, murmuró”).

\section{Conclusiones}

El análisis de las palabras clave de relatos gais y lésbicos ha evidenciado que la subjetividad y el deseo homosexual son un terreno de conflicto "colonizado" por el simbolismo de dominio heteronormativo. De hecho, la exageración de las características de género de los protagonistas es una imitación un tanto esperpéntica, en clave queer, de la heterosexualidad hegemónica (queering of hegemonic heterosexuality, según la expresión afortunada de Baker). Las ensoñaciones eróticas de los gais resultan pobladas de hombretones hiperviriles y ultramachos, dotados de un sex appeal animal, entregados a prácticas de dominación, en las que el individuo pasivo es con frecuencia humillado, simplemente por su rol de sumiso feminizado. En la mayoría de los casos, el pasivo coincide con la voz narrativa y disfruta sobremanera la experiencia de dominación, lo que revela rasgos de masoquismo narcisista. En retrospectiva, esta polarización extrema de los papeles sexuales, tajantemente repartidos entre penetrador y penetrado, no hace más que reproducir las jerarquías de valores y de poder en cuya cumbre está la masculinidad heterosexual tradicional, con todo su simbolismo fálico. Por consiguiente, la sexualidad gay queda retratada como mera genitalidad, despojada de todo intento de acercarse al otro para descubrirlo y, al final, fundirse con él. Lo que los resultados del análisis ofrecido parecen indicar es que, en el imaginario erótico de los homosexuales varones, la prestación compulsiva tiende a ser prioritaria sobre el propio placer, ya que la sexualidad suele reducirse a banco de pruebas para la 
virilidad del activo y la feminización del pasivo, lo cual, en definitiva, conlleva un empobrecimiento de la experiencia sexual, lastrada por la incapacidad para establecer lazos emocionales y expandir la gama de posibilidades de experimentar el goce físico.

Por otra parte, el sueño erótico de las usuarias lesbianas tiende a coincidir con una figura femenina fuertemente idealizada, denodada y protectora, encarnada en la figura de Xena, señora conquistadora de la antigua Hélade. Cuando, en cambio, las protagonistas no son heroínas sino mujeres comunes, sus pulsiones eróticas parecen encenderse a través de las miradas y, en general, en sus contactos físicos prevalecen los elementos léxicos que remiten a la ternura, a la complicidad y al deseo de protección. En general, el erotismo de las lesbianas parece orientado hacia el encuentro y la fusión con el ser amado, con el cual la voz narrativa aspira a construir una relación afectiva estable, para toda la vida. El miedo al abandono y a perder al ser amado, dominante en los relatos lésbicos, se refleja en la centralidad de los celos, rasgo que parece afianzar el estereotipo patriarcal de la mujer sentimental, tendencialmente insegura y emocionalmente dependiente de la persona amada. La "colonización" del deseo lésbico por parte del simbolismo heteronormativo se refleja también en el registro lingüístico en que se plasman las fantasías lésbicas, ya que los personajes femeninos rehúyen el lenguaje soez y socialmente ofensivo, prerrogativa de la comunicación de los varones, y son más proclives al empleo de hipocorísticos y de la derivación apreciativa.

Un dato significativo es que, en casos aislados, el comportamiento colocacional de los ítems clave desvela un intento de abrir una brecha en el machismo monolítico que impregna el imaginario erótico masculino. En cambio, las pautas colocacionales de las palabras clave del subcorpus lésbico no dejan entrever amagos de subversión del modelo femenino hegemónico, supeditado al poder del hombre, lo cual parece indicar que las autoras lesbianas -mayoritariamente hispanoamericanas según su variedad lingüística- tienen muy interiorizado el modelo de la "mujer protectora y maternal".

A la luz de estos resultados, siendo los estereotipos heteronormativos tan sutilmente ubicuos y penetrantes, cabe preguntarse hasta qué punto los homosexuales pueden "fiarse" de la autenticidad de su propio deseo erótico y si de verdad es posible superar la estigmatización e infravaloración de este colectivo fraguando modelos auténticamente alternativos de masculinidad y femineidad, p. ej., mediante la deconstrucción sistemática, la parodia y la subversión del imaginario simbólico patriarcal. 
El interrogante que queda sin respuesta, por la propia naturaleza del corpus de estudio, es el peso efectivo del machismo hispanoamericano en los resultados recabados. Si hubiese sido técnicamente posible distinguir los relatos producidos en la Península y en América, hubiéramos podido comprobar si el deseo erótico se construye de forma distinta a este y al otro lado del Atlántico. Por desgracia, el anonimato garantizado por el ciberespacio y por las identidades digitales ficticias no permiten un etiquetado fiable de la procedencia geográfica de los autores de los relatos que integran el corpus de estudio.

Con respecto a la metodología empleada, si bien es cierto que la perspectiva psicoanalítica ha sido ampliamente criticada por haber considerado, por largo tiempo, la homosexualidad como una psicosis de la cual el sujeto homosexual tenía que curarse, también es incontestable que las herramientas analíticas de Freud, a partir de su descripción del complejo de Edipo, constituyen ya un referente ineludible en el estudio del desarrollo psicosexual de cada individuo. En el caso del presente estudio, la triangulación de la metodología de corpus con los conceptos medulares del psicoanálisis y del construccionismo social ha permitido vislumbrar un hilo conductor entre palabras clave, permitiendo una interpretación menos subjetiva de los datos extraídos de los textos.

\section{Bibliografía}

Baker, Paul. 2004. Querying Keywords. Questions of Difference, Frequency and Sense in Keywords Analysis. Journal of English Linguistics 32(4): 346-359.

Baker, Paul. 2005. Public Discourses of Gay Men. London/New York: Routledge.

Baker, Paul. 20I4. Using Corpora to Analyze Gender. London/New York: Bloomsbury.

Baker, Paul. 20I8. Keywords: Signposts to objectivity? En Cermáková, Anna \& Mahlberg, Michaela (ed.) The Corpus Linguistics Discourse: in honour of Wolfgang Teubert, Amsterdam/Philadelphia: John Benjamins, 77-94.

Ciccone, Stefano. 20I9. Maschi in crisi? Oltre la frustrazione e il rancore. Torino: Rosenberg \& Sellier.

Connell, Raewyn. [1995] I996. Maschilità. Milano: Feltrinelli.

De Lauretis, Teresa. I991. Queer Theory: Lesbian and Gay Sexualities (Ed.). Special issue of Differences: A Journal of Feminist Cultural Studies, 3(2). Indiana University Press.

Fagioli, Massimo. 1965. J. Mallet De l"homosexualité psychotique (L"omosessualità psicotica) International Universities Press, p. 72 y sgg.". Rivista di Psicoanalisi II (3): 302-302.

Foucault, Michel. I969. L"archéologie du savoir. Paris: Gallimard. 
Foucault, Michel. [I975] I997. Asili. Sessualità. Prigioni. En Dal Lago, Alessandro (ed.) Prigioni e dintorni. Detti e scritti tratti dall"Archivio Foucault. Milano: Feltrinelli.

Freud, Sigmund. [I9I0] I976. Obras Completas. Volumen 11 (1910). Cinco conferencias sobre psicoanálisis. Un recuerdo infantil de Leonardo da Vinci y otras obras. Buenos Aires: Amorrortu editores S. A.

Freud, Sigmund. [1955a] I976. Obras Completas. Volumen 17 (1917-19). De la historia de una neurosis infantil y otras obras (caso del Hombre de los Lobos). Buenos Aires: Amorrortu editores S. A.

Freud, Sigmund. [I955b] I976. Obras Completas. Volumen 18 (1920-22). Más allá del principio del placer. Psicología de las masas y análisis del yo y otras obras. Buenos Aires: Amorrortu editores S. A.

Freud, Sigmund. [i96ra] I976. Obras completas. Volumen 19 (1923-25). El yo y el ello y otras obras. Buenos Aires: Amorrortu editores S. A.

Freud, Sigmund. [196Ib] I976. Obras Completas. Volumen 21 (1927-31). El porvenir de una ilusión, El malestar de la cultura y otras obras. Buenos Aires: Amorrortu S. A.

Gabrielatos, Costas. 20I8. Keyness analysis: Nature, metrics and techniques. En Taylor, Charlotte \& Marchi, Anna (ed.) Corpus Approaches to Discourse: A Critical Review. London: Routledge, 225-258.

Gesuè, Angela. 20I8. Omosessualità. https://www.spiweb.it/spipedia/omosessualita-cura-angela-gesue/ [Acceso 03/202I].

Giddens, Anthony \& Sutton, Philip W. 20I7. Essential Concepts in Sociology. Cambridge: Polity Press.

Harvey, Keith \& Shalom, Celia. I997. Language and Desire. Encoding Sex, Romance and Intimacy. London/New York: Routledge.

Kilgarriff, Adam; Rychlý, Pavel; Smrž, Pavel \& Tugwell, David. 2004. The Sketch Engine. Information Technology: I05-II6.

King, Brian W. 20I5. Investigating digital sex talk practices. En Jones, Rodney H.; Chik, Alice \& Hafner, Christoph A. (ed.) Discourse and Digital Practices, London/New York: Routledge, I30-I43.

Kosofsky Sedgwick, Eve. I985. Between Men: English Literature and Male Homosocial Desire. Columbia University Press.

Lázaro Mora, Fernando A. I999. La derivación apreciativa. En Bosque, Ignacio \& Demonte, Violeta (ed.) Gramática descriptiva de la lengua española. Madrid: Espasa, $4645-4682$.

Leap, William. 20I5. Queer linguistics as critical discourse analysis. En Tannen, Deborah; Hamilton, Heidi E. \& Schiffrin, Deborah (ed.) The Handbook of Discourse Analysis. Oxford: Balckwell, 66r-680.

Louw, Bill. I993. Irony in the Text or Insincerity in the Writer? The Diagnostic Potential of Semantic Prosodies. En Baker, Mona; Gill, Francis \& Tognini-Bonelli, Elena (ed.) Text and Technology: In Honour of John Sinclair. Amsterdam/Philadelphia: John Benjamins, 240-25I. 
Milani, Tommaso M. 2013. Are "queers" really "queer"? Language, identity and samesex desire in a South African online community. Discourse \& Society 24(5): 6I533.

Morgenthaler, Fritz. I982. L'omosessualità. Psicoterapia e Scienze Umane XVI(I): 3-37. Motschenbacher, Heiko. 20I8. Corpus Linguistics in language and sexuality studies. Talking stock and looking ahead. Journal of Language and Sexuality 7(2): 145-74. Motschenbacher, Heiko. 20I9. Language and sexual normativity. En Barrett, Rusty \& Hall, Kira (ed.) Oxford Handbook of Language and Sexuality. Oxford: Oxford University Press. doi: I0.I093/oxfordhb/97801902I2926.0I3.I4

Partington, Alan S. 20I4. Evaluative prosody. En Aijmer, Karin \& Rühlemann, Christoph (ed.) Corpora and Evaluation. Cambridge: Cambridge University Press, 279-303.

Partington, Alan; Duguid, Alison \& Taylor, Charlotte. 2013. Patterns and Meanings in Discourse. Theory and Practice in Corpus-assisted Discourse Studies (CADS). Amsterdam/Philadelphia: John Benjamins.

Phillips, Martin. I989. Lexical Structure of Text. Birmingham: English Language Research.

Real Academia Española (RAE). 2009. Nueva gramática de la lengua española. Madrid: Espasa.

Real Academia Española (RAE). 20I4. Diccionario de la lengua española. Madrid: Espasa.

Scott, Mike. I997. PC analysis of key words - And key key words. System 25(2): 233245 .

Scott, Mike. I999. WordSmith Tools Help Manual. Version 3.o. Mike Scott/Oxford University Press.

Sinclair, John McH. I987. Collocation: a progress report. En Steele, Ross \& Threadgold, Terry (ed.) Language Topics. Essays in Honour of Michael Halliday. Amsterdam/Philadelphia: Benjamins, 319-332.

Sinclair, John McH. I996. The Search for Units of Meaning. Textus 9(I): 75-106.

Strelkov, Andrea Laura. 2004. ¿Identidad/es Gay? Estereotipos y singularidades. http:// www.memoria.fahce.unlp.edu.ar/tesis/te.645/te.645.pdf

Torres Arias, M. ${ }^{a}$ Antonieta. I992. El malentendido de la homosexualidad. Debate Feminista 5: 33I-342.

Valdez Vázquez, Daniel. 20I7. Las redes sociales en internet y la construcción de la ciberidentidad (cyberself). Revista Conexxión i6: 39-45.

Warner, Michael. I99I. Introduction: Fear of a Queer Planet. Social Text 29: 3-I7.

Zeeland, Steven. I996. The Masculine Marine. New York: Harrington Park Press. 
